\title{
Leukemic Mantle Cell Lymphoma: Clinical and Pathologic Spectrum of Twenty-Three Cases
}

\author{
Ellen Schlette, M.D., Raymond Lai, M.D., Ph.D., Mihaela Onciu, M.D., Dorota Doherty, Ph.D., \\ Carlos Bueso-Ramos, M.D., Ph.D., L. Jeffrey Medeiros, M.D. \\ Departments of Hematopathology (ES, RL, MO, CB-R, LJM) and Biostatistics (DD), University of Texas \\ M.D. Anderson Cancer Center, Houston, Texas
}

\begin{abstract}
Twenty-three patients with marked leukemic involvement by mantle cell lymphoma (MCL) are described. Each patient had an absolute lymphocyte count more than $10 \times 10^{9} / \mathrm{L}$. The diagnosis of MCL was supported by compatible immunophenotypic findings and the $t(11 ; 14)(q 13 ; q 32)$ in all cases. Morphologically, these cases exhibited a spectrum of findings that we divided into two groups using a cutoff of $20 \%$ large or blastoid cells (log rank test, $P=.004)$. Patients with small-cell $(<20 \%)$ morphologic features survived longer than patients with large/blastoid ( $\geq 20 \%$ ) morphologic features, $(P=.003$, log rank test). The most common additional karyotypic abnormality identified in this study involved chromosome 17, in 13 of 23 (56.5\%) cases, which correlated with p53 overexpression but not with cytologic features. We conclude that cytologic features of MCL predict the prognosis of patients with marked leukemic involvement. Chromosome 17 abnormalities are common in leukemic MCL, may be involved in pathogenesis, and are associated with p53 expression.
\end{abstract}

KEY WORDS: Conventional cytogenetics, Leukemia, Mantle cell lymphoma, $t(11 ; 14)$.

Mod Pathol 2001;14(11):1133-1140

Mantle cell lymphoma (MCL) is a distinctive type of non-Hodgkin's lymphoma included in the revised European-American lymphoma (REAL) and World Health Organization (WHO) classification schemes $(1,2)$. Patients with MCL are mostly elderly, with a male predominance, and usually have nodal-based disease. Extranodal sites are also commonly involved. The characteristic molecular abnormality of

Copyright (C) 2001 by The United States and Canadian Academy of Pathology, Inc.

VOL. 14, NO. 11, P. 1133, 2001 Printed in the U.S.A.

Date of acceptance: July 6, 2001.

Address reprint requests to: Ellen Schlette, M.D., Department of Hematopathology, University of Texas M.D. Anderson Cancer Center, Box 72, 1515 Holcombe Blvd., Houston, TX 77030; e-mail: eschlett@ mdanderson.org; fax: 713-792-7273.
MCL is the $t(11 ; 14)(q 13 ; q 32)$, in which the CCND1 gene on 11q13 is juxtaposed with the immunoglobulin heavy-chain gene locus on 14q32, resulting in overexpression of cyclin D1.

Peripheral blood is often involved in patients with MCL. In a study by Cohen and colleagues (3), low-level involvement was observed in peripheral blood smears prepared from $77 \%$ of patients with MCL. However, overt leukemic involvement in patients with MCL is much less common. In a series of MCL cases described by Pittaluga and colleagues (4), only $10 \%$ of patients had an absolute lymphocyte count more than $10 \times 10^{9} / \mathrm{L}$, and this subset of patients had a worse prognosis (4).

Most studies of leukemic involvement by MCL have focused on patients who initially presented with nodal disease and subsequently developed leukemia. Patients who present primarily with leukemic involvement, with marked lymphocytosis similar to patients with other chronic lymphoproliferative disorders, are not well described in the literature. Furthermore, the wide morphologic spectrum of leukemic MCL has been not well described in peripheral blood and bone marrow. High-grade variants of MCL (blastoid, large cell) involving peripheral blood have been described recently and correlated with poorer survival (5-8).

For this study, we collected a group of 23 patients who presented primarily with leukemic involvement by MCL, each shown to carry the $t(11 ; 14)$ (q13; q32), to describe the clinical and pathologic spectrum. Each patient had an absolute lymphocyte count of more than $10 \times 10^{9} / \mathrm{L}$ at the time of initial evaluation at our institution. The immunophenotype of the neoplastic cells supported the diagnosis of MCL, including cyclin D1 overexpression in 20 of 21 cases assessed.

\section{METHODS AND MATERIALS}

\section{Study Group}

Twenty-three patients with MCL and marked lymphocytosis of more than $10 \times 10^{9} / \mathrm{L}$ at time of 
diagnosis, referred to our institution between 1993 and 2000, were included in the study group. Cases were included only if the diagnosis of MCL was supported by the presence of the $t(11 ; 14)$, demonstrated by conventional cytogenetic analysis performed at our institution. Cases without cytogenetically proven $t(11 ; 14)$ were not included in the study. The diagnoses established at the referring institutions for these cases included the following: chronic lymphocytic leukemia $(n=16)$, mantle cell lymphoma in leukemic phase $(n=5)$, splenic lymphoma with villous lymphocytes $(n=1)$, and precursor B-cell acute lymphoblastic leukemia $(n=1)$.

\section{Morphologic Methods}

Wright-Giemsa-stained peripheral blood and bone marrow aspirate smears were reviewed, as were hematoxylin-eosin stained histologic sections of bone marrow aspiration clot and core biopsy specimens. All cases were reviewed by four hematopathologists individually after a consensus for the morphologic criteria was reached. In each case, manual 100-cell differential counts of the neoplastic cells were performed by one of the authors (ES). The morphologic types of neoplastic cells fell into four general categories: small and round; small and irregular (some cleaved); large with prominent nucleoli (many of which resemble prolymphocytes); and blastoid cells. Using a cutoff of $20 \%$, chosen on the basis of statistical analysis (see below), these cases were collapsed into two groups: cases with fewer than $20 \%$ large/blastoid cells and cases with at least $20 \%$ large/blastoid cells.

\section{Immunohistochemical Methods}

Immunohistochemical staining for cyclin D1 was performed on formalin-fixed, paraffin-embedded tissue sections of either bone marrow aspirate clot $(n=17)$ or core biopsy tissue sections $(n=4)$ in 21 cases. In 2 cases, paraffin blocks were not available. After deparaffinization and rehydration in graded alcohols and xylene, endogenous peroxidase was blocked with hydrogen peroxide. Heat-induced epitope retrieval was performed by heating slides in EDTA buffer at $\mathrm{pH}$ 8.0, using a Black and Decker Handy Steamer Plus, and then cooled for twenty minutes. Most cases were assessed for cyclin D1 expression, for the purpose of this study, using the AM29 antibody (1:15, Zymed Laboratories Inc, South San Francisco, CA; $n=17$ ). In 4 cases, the DCS-6 (1:350, DAKO Corporation, Carpinteria, CA) antibody was used at the time of initial diagnosis. The immunostaining was completed according to methods described previously using the LSAB2 detection kit (DAKO), with appropriate positive and negative controls.
Immunohistochemical staining for p53 was performed on a subset of 19 cases using formalin-fixed, paraffin-embedded tissue sections of bone marrow and the DO-7 antibody (1:50, DAKO). P53 was considered positive if at least $10 \%$ of the neoplastic cells exhibited unequivocal nuclear staining.

\section{Flow Cytometry Studies}

Peripheral blood $(n=11)$ and bone marrow aspirate $(n=12)$ specimens in all patients were assessed using 3-color flow cytometric analysis and a FACScan (Becton-Dickinson, San Jose, CA) instrument. Lymphocytes were gated for analysis using CD45 expression and right-angle light scatter as described by Borowitz and colleagues (9). Fluorescein isothiocyanate (FITC)- and phycoerythrin (PE)-conjugated IgG1 and IgG2 antibodies were used as negative controls, and cursors were set to include more than $95 \%$ of events as negative. The panel of antibodies, conjugated to FITC or PE, included reagents specific for CD3, CD4, CD5, CD7, CD10, CD19, CD20, CD23, FMC-7, and immunoglobulin kappa and lambda light chains (Becton-Dickinson).

\section{Conventional Cytogenetic Studies}

Conventional G-band karyotype analysis was performed on bone marrow aspirate specimens from 22 patients and lymph node tissue from 1 patient. Cells were placed in $10 \mathrm{~mL}$ of Ham's F10 medium with $20 \%$ fetal calf serum at a concentration of $2 \times 10^{6}$ to $4 \times 10^{6}$ nucleated cells per milliliter. The culture was incubated overnight at $37^{\circ} \mathrm{C}$ (approximately 24 hours). Standard harvesting procedures were used. Colcemid $(0.1 \mathrm{~mL} / 10 \mathrm{~mL})$ was added to the culture for 30 minutes. For the hypotonic treatment, $0.075 \mathrm{M} \mathrm{KCl}$ was used for $30 \mathrm{~min}$ utes at room temperature. The fixation procedure consisted of 3 changes of methanol-glacial acetic acid (3:1), with a 10-minute waiting period between each change. The Thermaton drying chamber (Thermaton Industries, Holland MI) was used for slide preparation. Slides were placed in a $60^{\circ} \mathrm{C}$ oven overnight in preparation for Giemsa trypsin $G$ banding. A maximum of 20 metaphases was analyzed. The karyotype formulas were written using the International System for Human Cytogenetic Nomenclature (ISCN; 10).

\section{Statistical Methods}

To determinate the optimal percentage of large/ blastoid cells to use as a cut-off to correlate with patient survival, various candidate cut-off values (i.e., $10 \%, 15 \%, 20 \%$, and $25 \%$ ) were directly compared, and all were statistically significant. Because the direct comparison with survival did not lead to 
a conclusive choice of a cut-off point, an alternative method was employed, using survival tree analysis for survival data, which allows classifying patients according to their risk of death.

\section{Survival Analysis}

Survival probabilities were estimated using Kaplan-Meier estimates. The log rank test was used to compare survival between morphological groups. The date of original diagnosis in most cases was available as month and year, without a specific day. In two cases, only the year was available. For the purpose of this analysis, all cases without a specific day were set to the middle of the month (i.e., the 15th). In the two cases for which only the year of initial diagnosis was available, the most conservative estimate of the date (i.e., 12/31) was used. However, we also tested other arbitrarily chosen dates of diagnosis for these two cases, and all dates yielded statistically significant differences between the groups.

\section{RESULTS}

\section{Clinical Data}

There were 18 men and 5 women with a median age of 68 years (range, 40-74 years). The median time from initial diagnosis at another hospital until referral to our institution was 8 months (range, less than 1-120 months). Twelve patients received 1 or more chemotherapeutic regimens, and 11 patients did not receive any therapy before evaluation at our institution.

Physical examination revealed splenomegaly in 22 of $23(96 \%)$ patients, ranging from "palpable" to extending $24 \mathrm{~cm}$ inferior to the left costal margin. Seven patients underwent splenectomy during their disease course. Lymphadenopathy, usually involving multiple sites, was present in $16(70 \%)$ patients. In 8 patients, lymph nodes were more than 2 $\mathrm{cm}$ in maximum dimension, and in 8 patients, lymph nodes were less than $2 \mathrm{~cm}$ in maximum dimension.

The median white blood cell count at time of referral to our institution was $75.7 \times 10^{9} / \mathrm{L}$, with a range from 19 to $689 \times 10^{9} / \mathrm{L}$ (reference range, 4.0-11.0 $\times 10^{9} / \mathrm{L}$ ). The median absolute lymphocyte count was $64.4 \times 10^{9} / \mathrm{L}$, with a range from 11 to $561 \times 10^{9} / \mathrm{L}$ (reference range, $1.0-4.8 \times 10^{9} / \mathrm{L}$ ). Clinical and laboratory data are summarized in Table 1.

Clinical history and follow-up were available for 23 patients, and the median time from initial diagnosis at the referring hospital to either death or final follow-up was 29 months (range, 2-126 months). Eleven patients died and 12 patients remained alive at last follow-up.

\section{Morphologic Findings}

The morphologic spectrum of MCL cells in peripheral blood and bone marrow aspirate smears from the cases in this study was wide. Small cells, 2 times the size of an erythrocyte, predominated in most cases. These cells had irregular to cleaved nuclear contours, occasionally with small nucleoli, as is most often seen in MCL (Fig. 1A), or had small round nuclei with clumped chromatin, resembling the cells of chronic lymphocytic leukemia (Fig. 1B). All cases had at least rare cells with high-grade morphologic features, which included large nucleolated cells and/or blastoid cells, all more than 3 times the size of an erythrocyte. The nucleolated cells had a single, prominent nucleolus, often centrally located, with abundant cytoplasm, resembling classic prolymphocytes (prolymphocytoid), or had less cytoplasm with irregular nuclear contours and prominent nucleoli (Fig. 1C). Blastoid MCL cells were smaller than prolymphocytoid cells, with fine, open chromatin, absent or inconspicuous nucleoli, and scant cytoplasm (Fig. 1D). The largest cells were more than 4 times the size of an erythrocyte, with irregular nuclear contours, multiple

TABLE 1. Summary of Clinical and Laboratory Findings in 23 Cases of Leukemic Mantle Cell Lymphoma (MCL)

\begin{tabular}{lcc}
\hline \multicolumn{1}{c}{ Parameter } & Small-Cell MCL $(n=15)$ & Large/Blastoid MCL $(n=8)$ \\
\hline Age, y (range) & $68(40-74)$ & $68(58-72)$ \\
Gender & $13 \mathrm{M}: 2 \mathrm{~F}$ & $5 \mathrm{M}: 3 \mathrm{~F}$ \\
Median follow-up (mo) & $42(6-72)$ & $21.5(6-126)$ \\
Status at last follow-up & 4 dead, 11 alive & 7 dead, 1 alive \\
Median WBC count at evaluation $\times 10^{9} / \mathrm{L}$ (range) & $70(19-698)$ & $107.3(19-405)$ \\
Median absolute lymphocyte count $\times 10^{9} / \mathrm{L}$ (range) & $39.9(12-648)$ & $78.5(11-289)$ \\
Median Hgb, g/L (range) & $12(6.5-14)$ & $9.6(7.5-12.8)$ \\
Lymphadenopathy (cm) & $>2 \mathrm{~cm}: 5$ patients & $>2 \mathrm{cm:} 2$ patients \\
& $<2 \mathrm{~cm}: 8$ patients & $<2 \mathrm{~cm}: 4$ patients \\
& Not palpable: 2 patients & Not palpable: 1 patient \\
Spleen size (cm below left costal margin) & & Not reported: 1 patient \\
& $3-24$ & $3-10$ \\
\end{tabular}

WBC, white blood cell count; Hgb, hemoglobin. 
nucleoli, and moderately abundant basophilic cytoplasm (Fig. 1E).

In 15 cases, small MCL cells predominated, and fewer than $20 \%$ of the lymphocytes in these cases had large/blastoid morphology. Nine cases were composed of small irregular cells, and 6 cases were composed of small round cells. The median percentage of the large (including prolymphocytoid) or blastoid cells was $7 \%$ (range, $1-17 \%$ ). In 8 cases, at least $20 \%$ of the MCL cells had large/blastoid morphology, 5 predominantly large and 3 predominantly blastoid. The median percentage of large or blastoid cells in these cases was $49 \%$ (range, $22-90 \%$ ).

\section{Bone Marrow Aspirate Clot and Biopsy Sections}

Bone marrow aspirate clot and biopsy specimens were involved in all cases, and the percentage of MCL cells in these specimens varied from 20 to $95 \%$. The predominant pattern of infiltration by
MCL was interstitial in 9 cases and diffuse in 6 cases. Combined patterns were seen in 8 cases: 3 interstitial and diffuse, 4 interstitial and nodular, and 1 interstitial and paratrabecular.

\section{Immunophenotypic Findings}

Flow cytometric immunophenotypic studies were performed in 23 cases. In every case, the neoplastic cells were positive for CD5, CD19, CD20, and monotypic immunoglobulin light chain (kappa 18; lambda 4). FMC-7 was expressed in 20 of $22(91 \%)$ cases. Three of 23 (13\%) cases were positive for CD23.

\section{Immunohistochemical Findings}

Cyclin D1 over-expression was detected immunohistochemically in 20 of 21 tumors assessed (Fig. 2). In each positive case unequivocal nuclear stain-

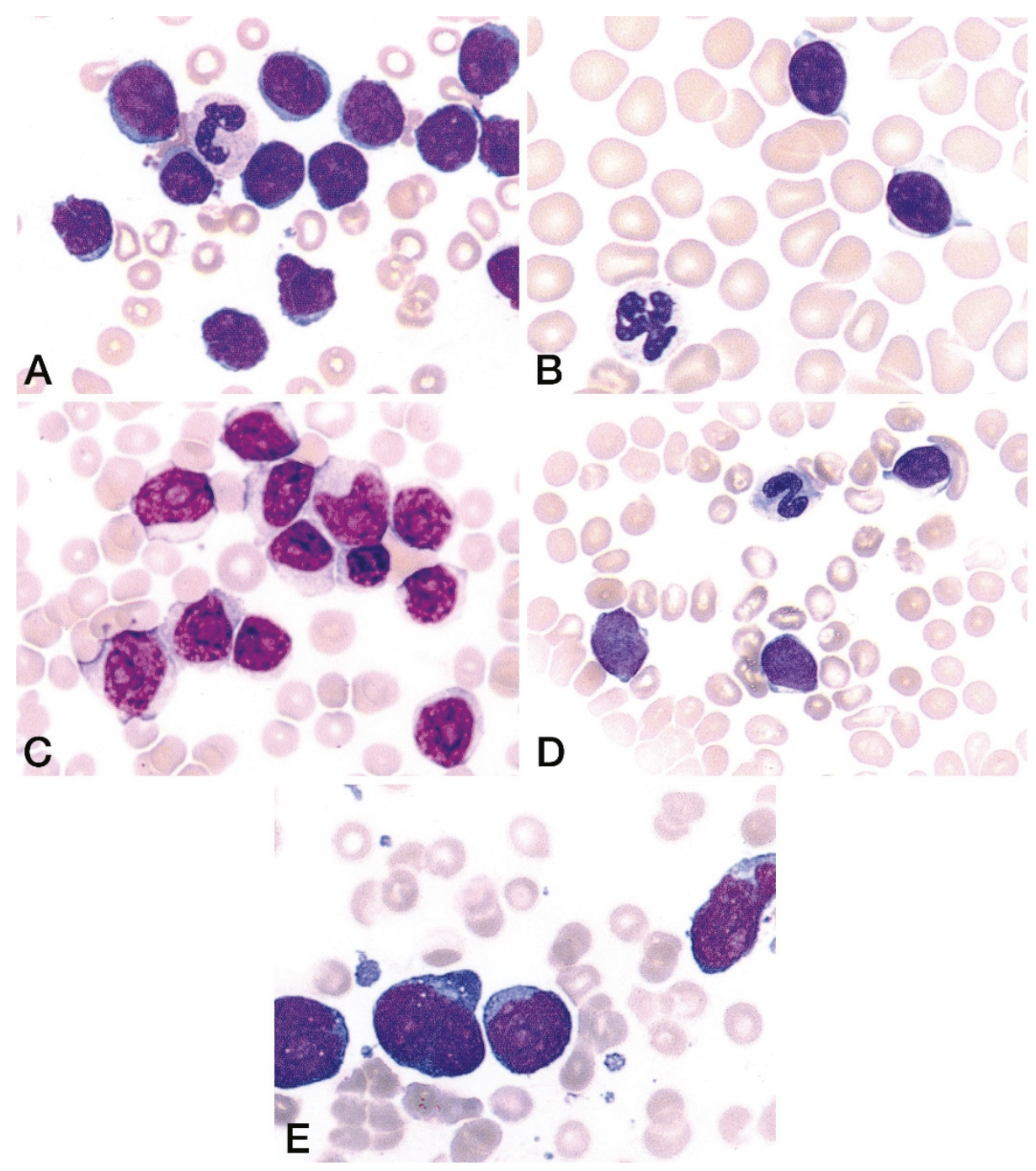

FIGURE 1. A, small-cell MCL with irregular nuclei and scant cytoplasm, typical of MCL. (Wright-Giemsa, 1000×). B, small-cell MCL cells with smooth nuclear contours and clumped chromatin (Wright-Giemsa, 1000×). C, large nucleolated MCL cells resembling prolymphocytes. Occasional nucleolated cells have irregular nuclear contours (Wright-Giemsa, 1000×). D, blastoid MCL cells with fine nuclear chromatin and scant cytoplasm (Wright-Giemsa, $1000 \times$ ). E, large MCL cells with multiple nucleoli and moderately abundant basophilic cytoplasm $($ Wright-Giemsa, 1000×). 
ing of MCL cells was identified. In two cases, paraffin blocks were not available for analysis.

P53 expression was assessed in 19 cases. These cases were chosen on the basis of available unstained tissue sections. Nine cases were positive (at least $10 \%$ of MCL cells positive) (Fig. 3), and 10 cases were negative (less than $10 \%$ of MCL cells positive).

\section{Cytogenetic Findings}

All cases had cytogenetic evidence of the $t(11$; 14) (q13;q32). In one case, the $t(11 ; 14)$ was the sole abnormality. In 22 cases, additional abnormalities were present. The median number of additional abnormalities was 4.5 (range, $0-12$ ), with no difference in the median between the small-cell and large/blastoid groups. The most common additional abnormality involved chromosome 17, identified in $13(56.5 \%)$ cases. There was no correlation between specific chromosomal abnormalities and morphologic groups. The cytogenetic findings in these cases have been reported previously (11).

\section{Survival Analysis}

Patient survival correlated with morphologic findings. To determine which percentage of large/ blastoid cells would best correlate with poor prognosis, a direct comparison of survival versus percentage of large/blastoid cells was examined via log rank test. The following cut-offs for percentage of large/blastoid cells correlated with poorer survival: $10 \%(P=.014), 15 \%(P=.014), 20 \%(P=.003)$, and $25 \%(P=.008)$. This method, although demonstrating that the percentage of large/blastoid cells significantly predicted survival, did not yield a clear cut-off point. Survival tree analysis was then used, which showed that a value of $20 \%$ large/blastoid cells best divided the study group into two risk groups. Four of 15 patients with predominantly small-cell MCL $(<20 \%$ large or blastoid cells) died; the median time from initial diagnosis to death was

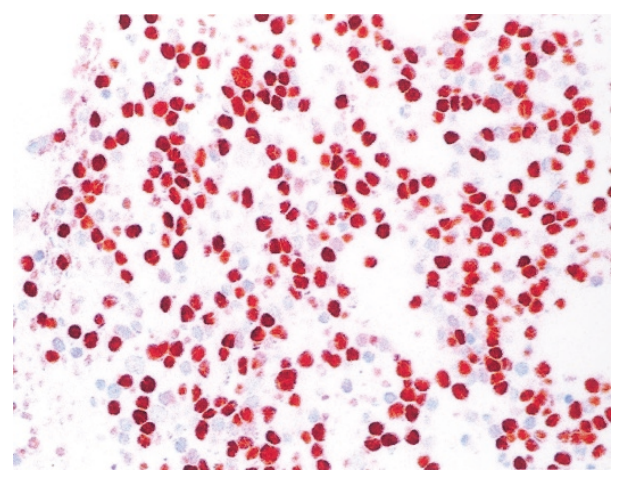

FIGURE 2. Immunohistochemical stain showing positive staining for cyclin D1 $(400 \times)$.

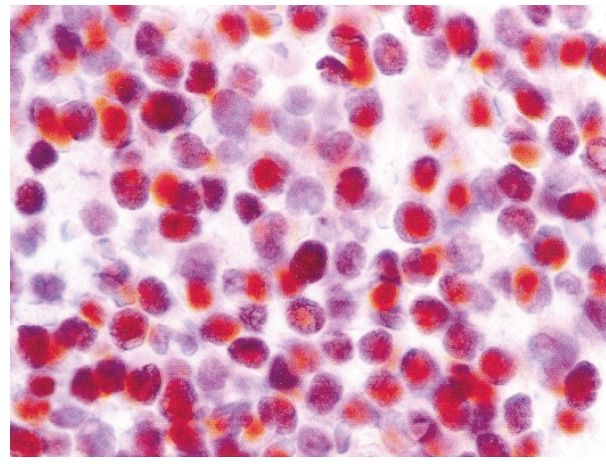

FIGURE 3. Immunohistochemical stain showing p53 overexpression. This case had a chromosome 17 abnormality, specifically, $-17(1000 \times)$.

34 months (range, 6-72 months). By contrast, 7 of 8 patients with large/blastoid MCL $(\geq 20 \%$ large or blastoid cells) died; the median time from initial diagnosis to death was 22.5 months (range, 7-126 months). The remaining patient who presented with blastoid cells at the time of initial diagnosis was alive at last follow-up; however, the interval from initial diagnosis was only 2 months. The median follow-up interval for patients who were alive at last follow-up was 32 months (range, 2-72 months). The difference in survival between patients with small-cell MCL and patients with large/ blastoid MCL was statistically significant $(P=.003$, log-rank test; Fig. 4).

\section{Correlation between Absolute Lymphocyte Count and Survival}

The median absolute lymphocyte count at time of referral was $78.8 \times 10^{9} / \mathrm{L}$ (range, $11.1-647.7 \times$ $\left.10^{9} / \mathrm{L}\right)$ in patients who died compared with $23 \times$ $10^{9} / \mathrm{L}$ (range, $12.2-158.8 \times 10^{9} / \mathrm{L}$ ) in patients who were alive at last follow-up.

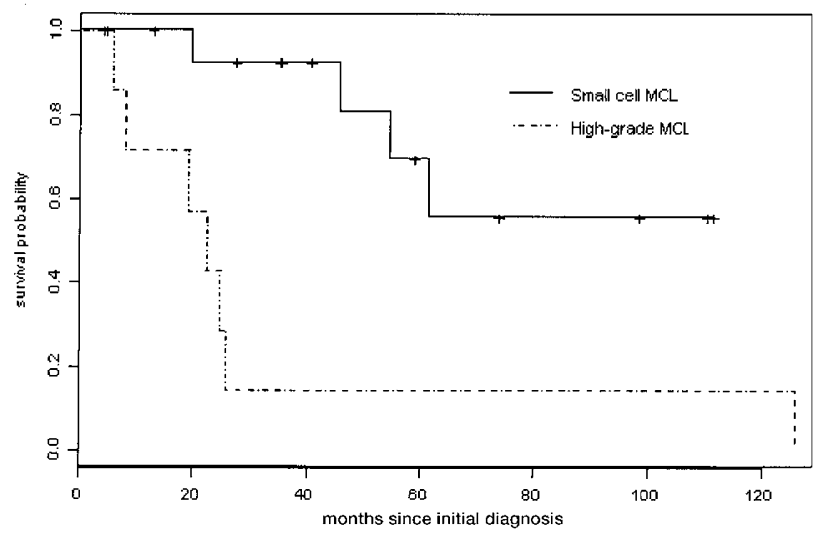

FIGURE 4. Morphology correlated with survival. Patients who presented with high-grade morphology (at least 20\% large blastoid cells) had a worse overall survival when compared with the case of patients who had small-cell morphology. 
Correlation between Cytologic Features, p53 Expression, and Chromosome 17 Abnormalities

Fourteen small-cell MCL were stained for p53; 6 cases were positive and 8 cases were negative. Five large/blastoid MCL were stained for p53; 3 cases were positive and 2 cases were negative. This difference was not statistically significant $(P>.05$; Fisher's exact test).

Eleven of 13 MCL with chromosome 17 abnormalities were assessed immunohistochemically for p53. Nine cases, 6 small cell and 3 large/ blastoid, showed increased p53 expression (at least $10 \%$ of cells positive). Two large/blastoid cases with $\operatorname{add}(17 \mathrm{p} 13)$ and $\operatorname{add}(17 \mathrm{p} 11.2)$ were negative for p53. Eight cases without chromosome 17 abnormalities were assessed for $\mathrm{p} 53$ and were negative. The correlation between chromosome 17 abnormalities and p53 expression was statistically significant. ( $P=.003$; Fisher's exact test).

\section{DISCUSSION}

Although involvement of the peripheral blood by MCL is frequent, in many studies in the literature patients had primarily nodal-based disease with a leukemic component, detected either at time of initial diagnosis or, more often, during the course of disease. Only a few studies have described patients who presented primarily with leukemic MCL $(4,6$, 7). Thus, we reviewed the clinicopathologic features of a series of 23 patients with MCL who presented initially with marked lymphocytosis. Each patient had an absolute lymphocyte count of more than $10 \times 10^{9} / \mathrm{L}$. All cases carried the characteristic cytogenetic abnormality, $\mathrm{t}(11 ; 14)(\mathrm{q} 13 ; \mathrm{q} 32)$, and 20 of 21 tumors assessed overexpressed cyclin D1. Flow cytometric studies performed on all cases assessed revealed compatible immunophenotypic findings: positive for monotypic immunoglobulin light chain, CD5, and CD19. CD23 was negative in 20 of 23 cases.

Similar to previous studies of leukemic MCL, most of our cases exhibited a mixture of neoplastic cells in peripheral blood or bone marrow aspirate smears $(3,5,6,12)$. In 15 cases, small MCL cells predominated. These cases had nuclei with round, irregular, or cleaved contours, the former group with some resemblance to chronic lymphocytic leukemia and the latter group resembling typical MCL cells. However, in every one of these cases, at least occasional large or blastoid cells (median 7\%) with prominent nucleoli or immature chromatin, respectively, were present.

By contrast, in 8 cases, the MCL cells were intermediate to large in size with high-grade cytologic features, including large, nucleolated cells resem- bling prolymphocytes and cells with immature chromatin resembling the blasts of acute leukemia. In one case with the largest cells, differential diagnosis with large-cell lymphoma was considered initially.

Peripheral blood involvement has been previously reported as an independent variable of poor prognosis in patients with MCL $(13,14)$. Previous studies also have reported that an absolute lymphocytosis of at least $10 \times 10^{9} / \mathrm{L}$ heralds shorter patient survival compared with patients with MCL and that an absolute lymphocyte count of less than $10 \times$ $10^{9} / \mathrm{L}$ (4). Our data support the premise that the absolute lymphocyte count has prognostic significance because patients who died had a higher median absolute lymphocyte count $\left(78.8 \times 10^{9} / \mathrm{L}\right)$ at time of referral than those patients who were alive at final follow-up $\left(23 \times 10^{9} / \mathrm{L}\right)$.

Multiple morphologic variants of MCL have been described, usually based on histologic examination of lymph node or extranodal biopsy specimens (15, 16). However, two studies have recently described high-grade variants of MCL in the peripheral blood. Singleton and colleagues (5) described six cases of blastoid MCL in leukemic phase, which correlated with the histologic findings in the lymph nodes. These cases were originally referred with various diagnoses including CLL, diffuse small-cleaved cell lymphoma, and diffuse large-cell lymphoma. The blastoid cells were described as medium-sized cells, with fine, blast-like chromatin and 1 to 2 prominent nucleoli (5). Similarly, Viswanatha and colleagues (7) described a group of six high-grade MCL in peripheral blood with features resembling those reported by Singleton et al. (5) However, these cases were diagnosed as blastic MCL based on the cytologic features of the leukemic cells, without tissue biopsy confirmation. These patients were found to have a relatively short median survival of 3 months (7). We also found that the cytologic features of MCL cells in peripheral blood and bone marrow are useful in predicting patient survival because 7 of 8 patients with large/blastoid cytologic features in this study died. In contrast, most patients with small-cell MCL had an indolent disease course, with clinical features resembling a chronic lymphoproliferative disorder. In this group, only 4 of 15 patients died, with a median time to death of 38.5 months (range, 21-67 months).

High-grade transformation of MCL is reported to occur in $32 \%$ of cases and was found in up to $70 \%$ of patients at autopsy in one study (17). The transformed tumors in that study were described as blastoid. However, these findings were based on examination of lymph nodes and did not describe highgrade MCL variants in the peripheral blood or bone marrow. Argatoff and colleagues (13) reported that $22 \%$ of MCL cases had increased numbers of 
lymphoblast-like cells in a variety of specimens including peripheral blood and bone marrow, more commonly detected during follow-up, and these patients had a shorter median survival than patients who did not have evidence of these cells. Cuneo and colleagues (18) reported six patients with $\mathrm{t}(11 ; 14)$ (q13; q32)-positive tumors, which were considered morphologically compatible with chronic lymphocytic leukemia, that underwent transformation in peripheral blood and bone marrow over time to atypical chronic lymphocytic leukemia or prolymphocytic leukemia. However, using the criteria of our study, these cases fall within the spectrum of leukemic MCL with high-grade cytologic features. Similarly, in this study, three patients with small-cell MCL developed large or blastoid cells over time. Two patients died with large/blastoid cells in bone marrow, and 1 patient still alive developed large-cell MCL documented in a liver biopsy specimen. Thus, our data also suggest that a subset of small-cell MCL undergo transformation to large-cell or blastoid MCL.

The presence of the $t(11 ; 14)(q 13 ; q 32)$ has been described in chronic lymphoproliferative disorders other than MCL, such as chronic lymphocytic leukemia (especially so-called atypical chronic lymphocytic leukemia), B-cell prolymphocytic leukemia, and lymphoplasmacytic lymphoma/leukemia (18-21). De Angeli and colleagues (21) described nine patients with $\mathrm{t}(11 ; 14)(\mathrm{q} 13 ; \mathrm{q} 32)$-positive tumors, which were categorized as atypical chronic lymphocytic leukemia based on peripheral blood morphology, in the absence of lymphadenopathy. However, they concluded that these cases most likely were part of the spectrum of MCL (21). An earlier report by Levy and colleagues (12) also concluded that cases with cyclin D1 overexpression and the $t(11 ; 14)(q 13 ; q 32)$ are closely related to MCL. Many morphologic variants of MCL have been recently described in the literature, which may account for the variety of lymphoproliferative disorders reported previously to carry the $\mathrm{t}(11$; 14) (q13;q32) $(8,16,20)$. Thus, it is our opinion that the presence of the $t(11 ; 14)$ in either peripheral blood or bone marrow, in conjunction with compatible immunophenotypic features, supports the diagnosis of MCL, even in the absence of biopsyproven lymph node disease.

Multiple cytogenetic abnormalities in addition to the $t(11 ; 14)$ were identified in $22(96 \%)$ cases in this study, as has been reported elsewhere (22-24). The most common additional abnormality involved chromosome 17 , in $57 \%$ of cases. These results support those of others who reported chromosome 17 abnormalities in leukemic MCL. Abnormalities involving chromosome 17 in this study specifically involved $17 \mathrm{p}$, the $p 53$ gene locus, in 5 cases. Chromosome 17 abnormalities were more commonly found in the large/blastoid group ( 6 of $8 ; 75 \%$ ) than in the small-cell group (7 of $15 ; 46 \%$ ), but this did not achieve statistical significance.

Alterations of chromosome 17 and p53 immunoreactivity, detected in $56.5 \%$ and $47.7 \%$ of cases in this study, respectively, suggest that the $p 53$ gene abnormalities may be involved in the pathogenesis of leukemic MCL. p53 gene mutations are among the most frequent abnormalities detected in human neoplasms and occur in approximately $14 \%$ of lymphoid neoplasms (25). The p53 gene product acts as a tumor suppressor by causing cell cycle arrest or apoptosis in response to DNA damage, allowing for repair and preventing propagation of mutations. $p 53$ gene mutations are reported to correlate with more aggressive hematological neoplasms, including aggressive forms of nodal and leukemic MCL $(21,26)$. p53 gene mutations commonly result in more stable forms of p53 protein, allowing assessment immunohistochemically. We also found that all types of structural or numerical chromosome 17 abnormalities correlated with p53 expression, not only those specifically involving $17 \mathrm{p}$. However, neither chromosome 17 abnormalities nor p53 immunoreactivity correlated with survival in this study. Previous studies have reported that MCL with $p 53$ gene mutations were associated with variant morphology and correlated with decreased overall survival when compared with cases without p53 gene mutations (26). In contrast, in other studies, p53 expression did not correlate with cytologic features, but only a small number of cases was assessed (27).

In summary, leukemic MCL can exhibit a wide spectrum of morphologic findings. We suggest that cell size and chromatin characteristics are useful for dividing these cases into two groups: small cell and large/blastoid. The large/blastoid group predicts poorer prognosis and includes cases with large cells, many of which are nucleolated and resemble prolymphocytes, as well as blastoid cells that resemble lymphoblasts. In this study, a cut-off of at least $20 \%$ large/blastoid cells best predicted poorer survival. Cytogenetic studies indicate that chromosome 17 abnormalities are common in leukemic MCL, are associated with p53 immunoreactivity, and may be involved in the pathogenesis of marked leukemic involvement.

Acknowledgments: The authors thank Kimberly Hayes, B.S., and Armand Glassman, M.D., for providing the cytogenetic data.

\section{REFERENCES}

1. Harris NL, Jaffe ES, Stein H, Banks PM, Chan JKC, Cleary ML, et al. A revised European-American classification of lym- 
phoid neoplasms: A proposal from the International Lymphoma Study Group. Blood 1994;84:1361-92.

2. Harris NL, Jaffe ES, Diebold J, Flandrin G, Muller-Hermelink HK, Vardiman J, et al. World Health Organization classification of neoplastic diseases of the hematopoietic and lymphoid tissues: Report of the Clinical Advisory Committee meeting-Airlie House, Virginia, November 1997. J Clin Oncol 1999;17:3835-49.

3. Cohen PL, Kurtin PJ, Donovan KA, Hanson CA. Bone marrow and peripheral blood involvement in mantle cell lymphoma. Br J Haematol 1998;101:302-10.

4. Pittaluga S, Verhoef G, Criel A, Maes A, Nuyts J, Boogaerts M, et al. Prognostic significance of bone marrow trephine and peripheral blood smears in 55 patients with mantle cell lymphoma. Leuk Lymphoma 1996;21:115-25.

5. Singleton TP, Anderson MM, Ross CW, Schnitzer B. Leukemic phase of mantle cell lymphoma, blastoid variant. Am J Clin Pathol 1999;111:495-500.

6. Wong KF, Chan JKC, So JC, Lo SS. Mantle cell lymphoma in leukemic phase: characterization of its broad cytologic spectrum with emphasis on the importance of distinction from other chronic lymphoproliferative disorders. Cancer 1999; 86:850-7.

7. Viswanatha DS, Foucar K, Berry BR, Gascoyne RD, Evans HL, Leith CP. Blastic mantle cell leukemia: an unusual presentation of blastic mantle cell lymphoma. Mod Pathol 2000;13: 825-33.

8. Schlette E, Bueso-Ramos C, Giles F, Glassman A, Hayes K, Medeiros LJ. Mature B-cell leukemias with $>55 \%$ prolymphocytes. A heterogeneous group that includes an unusual variant of mantle cell lymphoma. Am J Clin Pathol 2001;115: 571-81.

9. Borowitz MJ, Guenther KL, Shults KE, Stelzer GT. Immunophenotyping of acute leukemia by flow cytometric analysis. Use of CD45 and right-angle light scatter to gate on leukemic blasts in three-color analysis. Am J Clin Pathol 1993;100:53440 .

10. Mitelman F. Catalog of chromosome aberrations in cancer. 5th ed. New York: Wiley-Liss; 1994.

11. Onciu M, Schlette E, Medeiros LJ, Abruzzo LV, Keating M, Lai R. Cytogenetic findings in mantle cell lymphoma. Cases with a high level of peripheral blood involvement have a distinct pattern of abnormalities. Am J Clin Pathol (in press).

12. Levy V, Ugo V, Delmer A, Tang R, Ramond S, Perrot JY, et al. Cyclin D1 overexpression allows identification of an aggressive subset of leukemic lymphoproliferative disorder. Leukemia 1999;13:1343-51.

13. Argatoff LH, Connors JM, Klasa RJ Horsman DE, Gascoyne RD. Mantle cell lymphoma: a clinicopathologic study of 80 cases. Blood 1997;89:2067-78.

14. Samaha H, Dumontet C, Ketterer N, Moullet I, Thieblemont C, Bouafia F, et al. Mantle cell lymphoma: a retrospective study of 121 cases. Leukemia 1998;12:1281-7.
15. Lardelli P, Bookman MA, Sundeen J, Longo DL, Jaffe ES. Lymphocytic lymphoma of intermediate differentiation. Morphologic and immunophenotypic spectrum and clinical correlations. Am J Surg Pathol 1990;14:752-63.

16. Zoldan MC, Inghirami G, Masuda Y, Vandekerckhove F, Raphael B, Amorosi E, et al. Large-cell variants of mantle cell lymphoma: cytologic characteristics and p53 anomalies may predict poor outcome. Br J Haematol 1996;93:475-86.

17. Norton AJ, Matthews J, Pappa V, Shamash J, Love S, Rohatiner AZ, et al. Mantle cell lymphoma: natural history defined in a serially biopsed population over a 20 -year period. Ann Oncol 1995;6:249-56.

18. Cuneo A, Balboni M, Piva N, Rigolin GM, Roberti MG, Mejak $\mathrm{C}$, et al. Atypical chronic lymphocytic leukemia with $\mathrm{t}(11$; 14)(q13;q32): karyotype evolution and prolymphocytic transformation. Br J Haematol 1995;90:409-16.

19. Brito-Babapulle V, Ellis J, Matutes E, Oscier D, Khokhar T, MacLennan $\mathrm{K}$, et al. Translocation $\mathrm{t}(11 ; 14)(\mathrm{q} 13 ; \mathrm{q} 32)$ in chronic lymphoid disorders. Genes Chromosom Cancer 1992;5:158-65.

20. Hernandez JM, Mecucci C, Criel A, Meeus P, Michaux I, Van Hoof A, et al. Cytogenetic analysis of B-cell chronic lymphoid leukemias classified according to morphologic and immunophenotypic (FAB) criteria. Leukemia 1995;9:2140-6.

21. De Angeli C, Gandini D, Cuneo A, Moretti S, Bigoni R, Roberti MG, et al. BCL-1 rearrangements and p53 mutations in atypical chronic lymphocytic leukemia with $\mathrm{t}(11 ; 14)(\mathrm{q} 13$; q32). Haematologica 2000;85:913-21.

22. Wlodarska I, Pittaluga S, Hagemeijer A, De Wolf-Peeters C, Van den Berghe H. Secondary chromosome changes in mantle cell lymphoma. Haematologica 1999;84:594-9.

23. Cuneo A, Bigoni R, Rigolin GM, Roberti MG, Bardi A, Piva N, et al. Cytogenetic profile of lymphoma of follicle mantle lineage: correlation with clinicobiologic features. Blood 1999;93:1372-80.

24. Espinet B, Sole F, Woessner S, Bosch F, Florensa L, Campo E, et al. Translocation $(11 ; 14)$ (q13;q32) and preferential involvement of chromosomes 1, 2, 9, 13, and 17 in mantle cell lymphoma. Cancer Genet Cytogenet 1999;111:92-8.

25. Gaidano G, Ballerini P, Gong JZ, Inghirami G, Neri A, Newcomb EW, et al. p53 mutations in human lymphoid malignancies: association with Burkitt lymphoma and chronic lymphocytic leukemia. Proc Natl Acad Sci U S A 1991;88: 5413-7.

26. Greiner TC, Moynihan MJ, Chan WC, Lytle DM, Pedersen A, Anderson JR, et al. p53 mutations in mantle cell lymphoma are associated with variant cytology and predict a poor prognosis. Blood 1996;87:4302-10.

27. Louie DC, Offit K, Jaslow R, Parsa NZ, Murty VV, Schluger A, et al. P53 overexpression as a marker of poor prognosis in mantle cell lymphomas with $\mathrm{t}(11 ; 14)(\mathrm{q} 13 ; \mathrm{q} 32)$. Blood 1995; 8:2892-9. 